\title{
Phylogenetic correlograms and the evolution of body size in South American owls (Strigiformes)
}

\author{
José Alexandre Felizola Diniz-Filho ${ }^{I}$ and Carlos Eduardo Ramos de Sant'Ana ${ }^{2}$
}

\begin{abstract}
During the last few years, many models have been proposed to link microevolutionary processes to macroevolutionary patterns, defined by comparative data analysis. Among these, Brownian motion and Ornstein-Uhlenbeck (O-U) processes have been used to model, respectively, genetic drift or directional selection and stabilizing selection. These models produce different curves of pairwise variance between species against time since divergence, in such a way that different profiles appear in phylogenetic correlograms. We analyzed variation in body length among 19 species of South American owls, by means of phylogenetic correlograms constructed using Moran's I coefficient in four distance classes. Phylogeny among species was based on DNA hybridization. The observed correlogram was then compared with 500 correlograms obtained by simulations of Brownian motion and O-U over the same phylogeny, using discriminant analysis. The observed correlogram indicates a phylogenetic gradient up to 45 mya, when coefficients tend to stabilize, and it is similar to the correlograms produced by the O-U process. This is expected when we consider that body size of organisms is correlated with many ecological and life-history traits and subjected to many constraints that can be modeled by the O-U process, which has been used to describe evolution under stabilizing selection.
\end{abstract}

\section{INTRODUCTION}

In the last few years, considerable attention has been given to the analysis of quantitative trait evolution, especially in terms of linking microevolutionary processes (selection, drift, mutation) to macroevolutionary patterns, evaluated using comparative data (Felsenstein, 1988; Martins, 1994; Hansen and Martins, 1996). Among the many statistical models that have been proposed to fit comparative data, two have recently received more attention. The first is Brownian motion, that has often been used to describe evolution by random genetic drift (Felsenstein, 1985, 1988; Lynch, 1990; Martins, 1994). In this model, change in mean phenotype occurs at a constant rate and is non-directional. The relationship between pairwise interspecific variance $(\mathrm{Vb})$ and time since divergence $(\mathrm{t})$ is given by

$$
\mathrm{Vb}=\beta \mathrm{t}+\varepsilon
$$

where $\beta$ is the parameter (evolutionary rate) and $\varepsilon$ is the error term. The linear relationship of $\mathrm{Vb}$ to $t$ generated by Brownian motion is also expected under other genetic models, including constant directional selection (although B would be larger than expected by drift alone) and directional selection in fluctuating environments with a quick phenotypic response (Hansen and Martins, 1996).
On the other hand, evolution of complex polygenic traits subject to multiple selective pressures (especially stabilizing selection) is better modeled by the OrnsteinUhlenbeck (O-U) process (Felsenstein, 1988; Martins, 1994; Hansen and Martins, 1996). In this model, evolutionary changes are constrained by a constant force toward a central point, and $\mathrm{Vb}$ is related to $t$ by an exponential decrease, given by

$$
\mathrm{Vb}=\sigma^{2} / 2 \alpha\left(1-\mathrm{e}^{-2 \alpha t}\right)+\varepsilon
$$

where $\sigma^{2}$ is the variance of evolutionary change under a stochastic process and $\alpha$ is the restraining force of stabilizing selection. One of the properties of the $\mathrm{O}-\mathrm{U}$ process is that it "forgets" the past history (reducing the level of "phylogenetic inertia"). This explains the exponential decrease toward zero correlation between distantly related species (Felsenstein, 1988).

Since these two processes produce different curves of $\mathrm{Vb}$ in relation to t, they may be distinguished using phylogenetic correlograms (Gittleman and Kot, 1990; Gittleman et al., 1996), that indicate how the similarity among species changes with time of divergence between them. Martins (1994) also proposed a procedure to fit these two models to comparative data and estimate evolutionary rates in quantitative traits, using Felsenstein's

${ }^{1}$ Departamento de Biologia Geral, Instituto de Ciências Biológicas, Universidade Federal de Goiás, 
(1985) phylogenetic independent contrasts method to avoid the problem of heterocedasticity and independence in regressing the covariance matrix among species on a phylogenetic distance matrix.

We analyzed patterns of body size evolution in some species of South American owls (Aves: Strigiformes) by means of phylogenetic correlograms. Previous papers (Sant'Ana and Diniz-Filho, 1997; Diniz-Filho and Sant'Ana, 1998) indicated strong phylogenetic autocorrelation in body length, fitted by Cheverud's et al. (1985) autoregressive model. The objective of the present study was to compare the observed phylogenetic correlogram (estimating the relationship between $\mathrm{Vb}$ and $\mathrm{t}$ ) with correlograms constructed using simulated data of Brownian motion and $\mathrm{O}-\mathrm{U}$ processes running through the owl phylogeny, in an attempt to evaluate possible evolutionary factors involved in body size differentiation among these species.

\section{MATERIAL AND METHODS}

Nineteen species of owls (Aves: Strigiformes) found in South America were analyzed. Phylogenetic relationships among them were based on the phenogram provided by Sibley and Ahlquist (1990), which was constructed using DNA hybridization (Figure 1). Calibration of genetic distances was corrected for generation time, in such a way that one unit of genetic distance $\Delta \mathrm{T}_{50} \mathrm{H}$ is equal to $4.3 \mathrm{my}$, for each branch length in the phylogeny. Since there is no detailed information about phylogenetic relationships between these species within genera, soft polytomies were assumed when more than two species per genus were found, using the maximum within-genus genetic distance in the group (equal to 2.00, in Strix) as a conservative reference level. Polytomies in each genus were limited to a maximum of four species, in such a way that only part of the total number of species found in South America were analyzed. However, since there is a high similarity of species within genera of this group, especially for body length (elevated inertia at closest phylogenetic distances) (Sant' Ana and Diniz-Filho, 1997), this choice should not affect this analysis qualitatively. In fact, a conservative approach was used, and the two most different species in body length within each genus were chosen to be included in the analysis. Out of 11 genera of owls found in South America, 10 were included in the analysis. The only genus excluded was Ciccaba, which in fact has been considered

Figure 1 - Phylogeny based on Sibley and Ahlquist's (1990) DNA hybridization data and body lengths for the 19 species of owls analyzed here. Numbers indicate genetic distances, that can be converted into time (millions of years) by multiplying values by 4.3 .

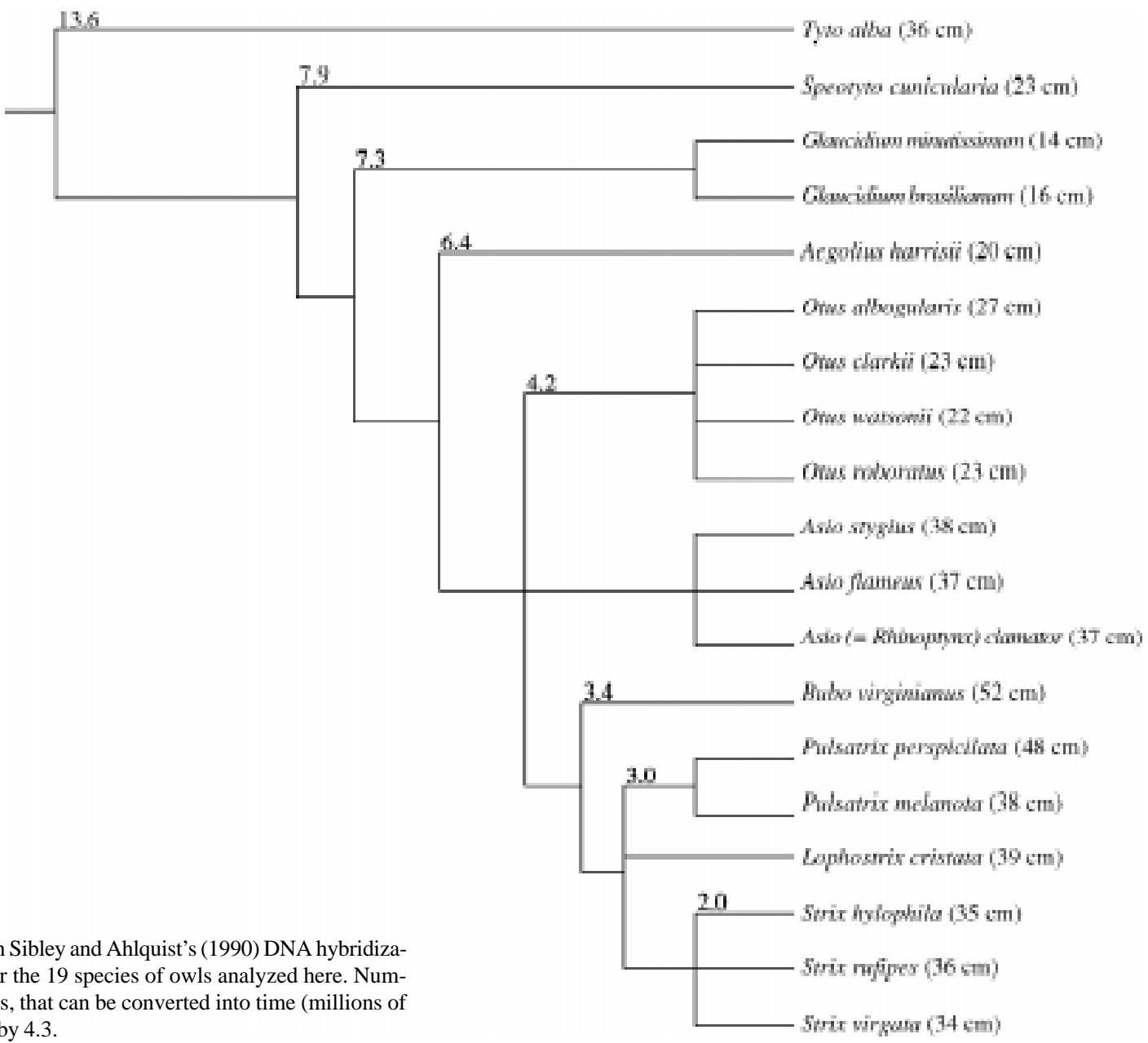


a synonym of Strix (Sibley and Monroe, 1990). See DinizFilho and Sant'Ana (1998) for a more detailed description of the species analyzed and phylogenetic relationships among them. For each species, body size data (total length) were obtained from Dunning (1989) and Sick (1997).

Phylogenetic patterns in body size were analyzed by a phylogenetic correlogram (Gittleman and Kot, 1990; Gittleman et al., 1996), that expresses changes in relative similarities between (pairs of) species as a function of time. Moran's I coefficients used in the correlograms are given by

$$
\mathrm{I}=(\mathrm{n} / \mathrm{S}) \Sigma_{\mathrm{i}} \Sigma_{\mathrm{j}} \mathrm{W}_{\mathrm{ij}}\left(\mathrm{y}_{\mathrm{i}}-\overline{\mathrm{y}}\right)\left(\mathrm{y}_{\mathrm{j}}-\overline{\mathrm{y}}\right) / \Sigma_{\mathrm{i}}\left(\mathrm{y}_{\mathrm{i}}-\overline{\mathrm{y}}\right)^{2}
$$

where $\mathrm{n}$ is the number of species analyzed, $\mathrm{y}$ is the variable analyzed (body length, in this case), Wij is the element of connectivity matrix $\mathbf{W}$, which contains the pairwise phylogenetic distances among species, and $\mathrm{S}$ is the sum of connections in each distance class. Positive significant coefficients in a given phylogenetic distance class indicate that species are similar at that level, whereas negative coefficients must be interpreted as dissimilarity at a given level. The value of Moran's I under the null hypothesis of no phylogenetic effect is given by $-1 /(n-1)$. Detailed procedures for computing the significance of each coefficient are given by Sokal and Oden (1978a,b) and Diniz-Filho (1999). For this study, Moran's I coefficients were estimated in four time distance classes across the phylogeny: $0-15,15-30,30-45$ and 45-60 million years since divergence.

To obtain a general picture of how phylogenetic correlograms reflect Brownian motion and $\mathrm{O}-\mathrm{U}$ processes of phenotypic evolution through this specific tree topol- ogy, 250 simulations were performed for each of the processes, with means and variances equal to the original traits, using the program PDAP, version 2.0 (Phenotypic Diversity Analysis Program, Jones et al., 1993). Each simulation was then analyzed by calculating phylogenetic correlograms, as described above, using the same distance classes used for the analysis of real data. These computations were performed with the program AUTOPHY, written in basic language and available from the authors upon request.

Correlograms generated by the two processes were compared using different approaches. Single classification analyses of variance (ANOVA) (Sokal and Rohlf, 1995) were used to compare the mean Moran's I of each class, between the two processes (Brownian motion and $\mathrm{O}-\mathrm{U}$ ). A multivariate comparison (using all the classes simultaneously) was performed using a multivariate analysis of variance (MANOVA) and linear discriminant analysis (Johnson and Wichern, 1992). This last procedure also permits a posteriori allocation of the observed correlogram into one of the two groups, using Mahalanobis distances. Pearson correlations between Moran's I and phylogenetic distance class (gradient correlations) were also calculated for each simulation, to evaluate the magnitude of the phylogenetic gradients generated by the two processes.

\section{RESULTS}

The correlogram of observed data (Figure 2) indicates a "phylogenetic gradient" up to 45 mya, when coefficients stabilized and became nonsignificant at a 5\% level. This profile indicates that closely related species tend to be similar (Moran's I $=0.532 ; \mathrm{P}<0.01$ ), and that this simi-

Body length

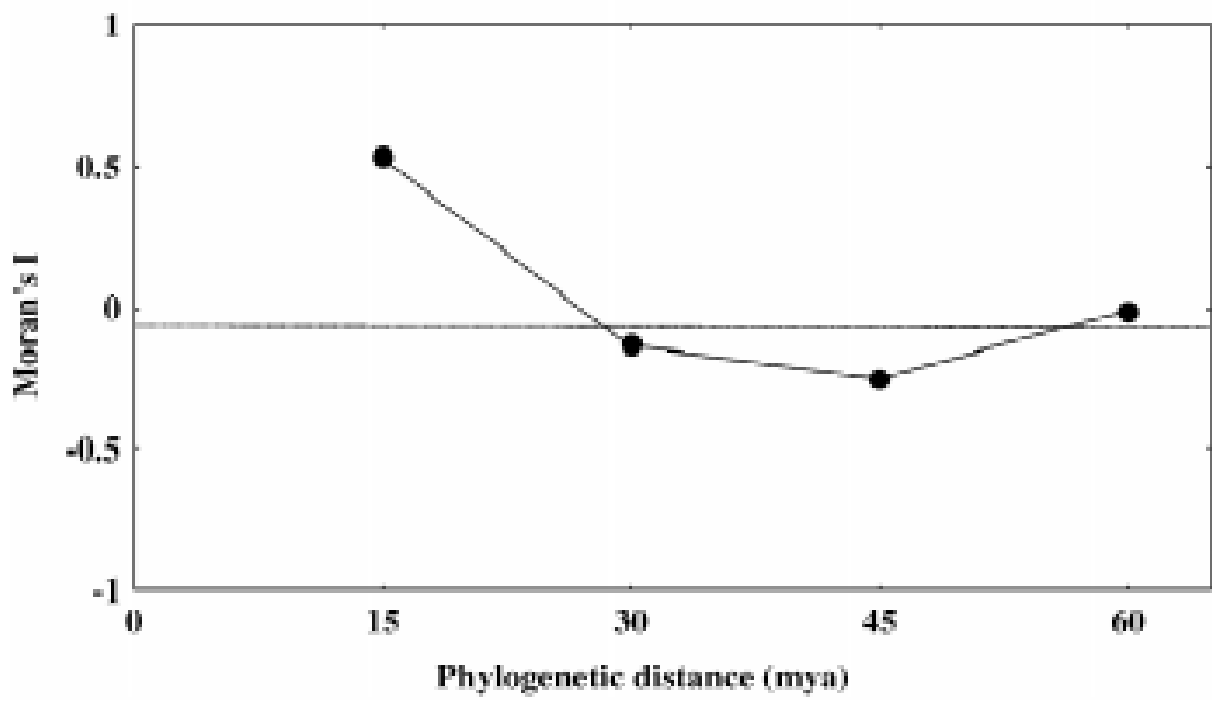

Figure 2 - Phylogenetic correlogram with four Moran's I coefficients for body size in 19 species of South American owls. Dashed line indicates the expected value under the null hypothesis of no autocorrelation. 

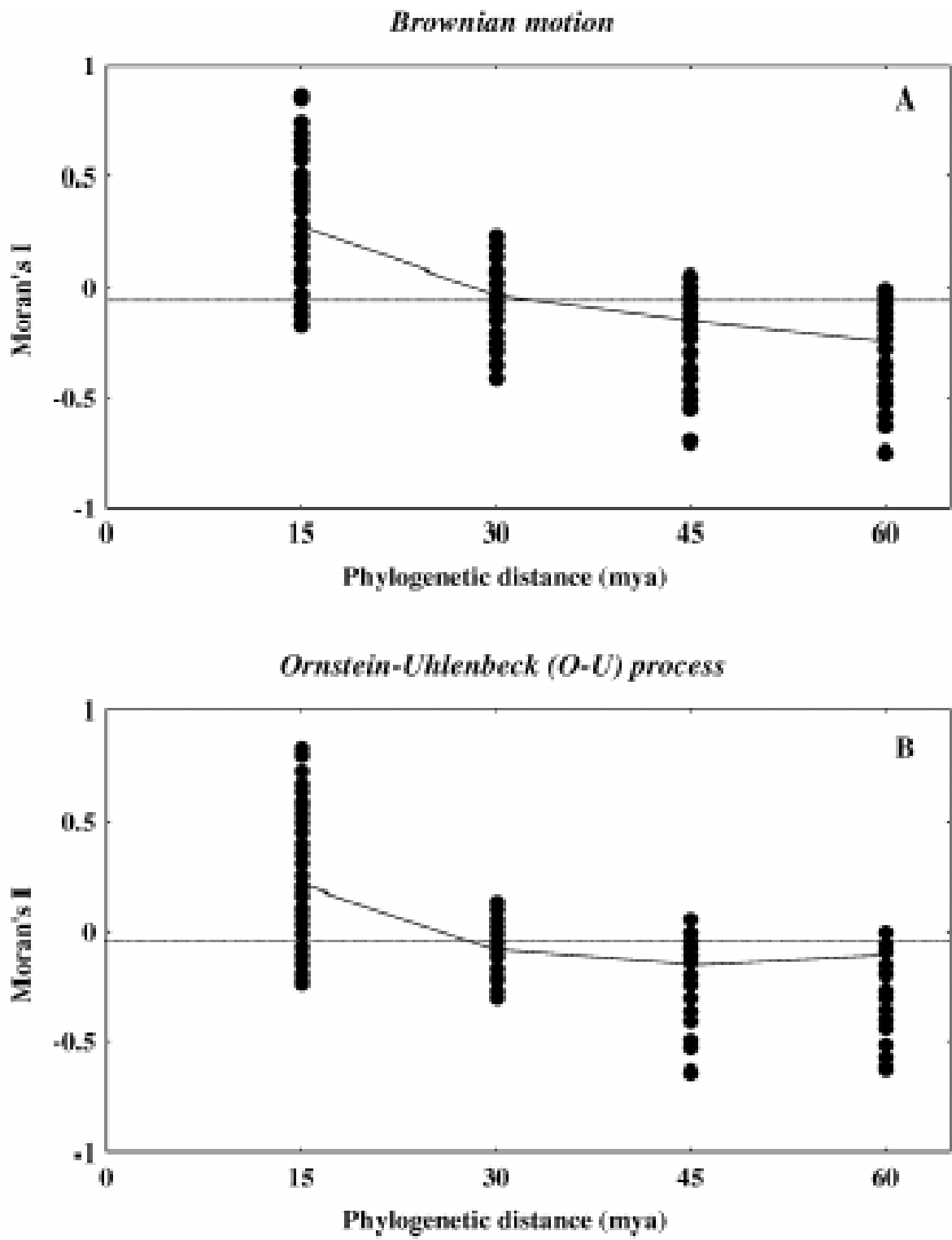

Figure 3 - Phylogenetic correlograms obtained by simulations of Brownian motion (A) and Ornstein-Uhlenbeck (O-U) (B) processes, on the phylogeny of 19 species of South American owls. Dashed lines indicate the expected value under the null hypothesis of no autocorrelation, and full lines indicate the average correlograms.

larity decreases with time. However, in the last distance class (45-60 mya), Moran's I coefficient was not significant at the 5\% level; consequently, more distantly related species are not necessarily the most dissimilar.

The correlograms obtained in simulations are similar to the real one, but differ for the two processes analyzed. An average continuous "phylogenetic gradient" appears for the Brownian motion (Figure 3A), with significant values of Moran's I in the first and last distance classes, and different signals. There was a monotonic decrease of coefficients in relation to phylogenetic distance in the average correlogram. As expected, closely related species tended to be similar (significant Moran's I at the
$5 \%$ level in $37 \%$ of the simulations), and distantly related species tended to be dissimilar (significant Moran's I in $35 \%$ of the simulations). On the other hand, the correlograms generated by simulating the $\mathrm{O}-\mathrm{U}$ process had similar results for the smallest distance class (significant Moran's I in $39.5 \%$ of the simulations), but differed considerably in the last one (Figure $3 \mathrm{~b}$ ). In the average $\mathrm{O}-\mathrm{U}$ profile closely related species were also similar, but the phenotypes became independent after the second distance class. The coefficients in the last distance class were significant in few simulations (18\%), in fact indicating that distantly related species tend to be independent.

Indeed, ANOVA indicated that the correlograms gen- 
erated by the two processes were similar, but differed in the last phylogenetic distance class, and only the means of the Moran's I in this class were different $(\mathrm{F}=25.339$; $\mathrm{P}<0.01)$. The multivariate comparison of correlograms supported the overall similarity, and that derived from MANOVA was equal to 0.932 (close to 1.0). However, the F-value associated with Wilks' lambda was 7.194, significant at $\mathrm{P}<0.01$. The inspection of the discriminant scores permits a visual evaluation of multivariate similarity between correlograms of the two processes (Figure 4).

Although the correlograms generated by the two processes were significantly different according to univariate and multivariate procedures, their overall similarity implies a relatively low inferential power. The observed Moran's I coefficients of body length in each distance class were within the $95 \%$ confidence interval obtained by simulations of the two processes. After discriminant analysis, it was possible to use Mahalanobis distances to allocate the observed correlogram to one of the two groups. The probability of allocation of the observed correlogram into the group of $\mathrm{O}-\mathrm{U}$ correlograms $(\mathrm{P}=0.537)$ is slightly larger than the probability of allocating it with correlograms generated by Brownian motion $(\mathrm{P}=0.463)$. The similarity of these probability values also reflects the similarity of the correlograms generated by the two processes.

Another analysis used to distinguish the two processes was to compare the Pearson correlation between Moran's I and phylogenetic distance (gradient correlations) (Figure 5). The median correlation for correlograms generated by Brownian motion was equal to -0.733 , which was significantly lower than the median of the correlation of the correlograms generated by the $\mathrm{O}-\mathrm{U}$ process $(-0.626)$ (Mann-Whitney test, $\chi^{2}=24.71,1$ d.f., $\mathrm{P}<0.001$ ). The lower median of O-U correlograms is caused by the stabi- lization in the decrease of the Moran's I coefficient in the last distance classes. The correlation between Moran's I and phylogenetic distance class in the real correlogram was equal to -0.671 . Using the distribution of correlations of Figure 4 it was possible to estimate the probability that a given gradient correlation (say, the observed value of -0.671) appears in one of the two processes. For the Brownian motion correlogram, the probability that a correlogram possesses a gradient with $\mathrm{r}<-0.671$ is 0.625 . The probability of finding a correlogram with such a gradient correlation among the $\mathrm{O}-\mathrm{U}$ correlograms is 0.38 . This indicates that the correlations in the Brownian motion correlograms are more frequently smaller (indicating stronger gradients) than the observed value, when compared with the correlations of the O-U correlograms. In fact, according to Figure 4, the observed correlation of 0.671 is a typical value in the distribution of correlations of O-U correlograms. So, once again, this gradient correlation analysis supports the conclusion that the overall shape of the observed correlogram was more similar to the $\mathrm{O}-\mathrm{U}$ than to the Brownian motion correlograms.

\section{DISCUSSION}

The comparison of the phylogenetic correlogram of body length for the South American owls with correlograms obtained by simulations of two stochastic processes suggests that the data are better explained by an OU process, which have been used to model effects of stabilizing selection (Felsenstein, 1988; Martins, 1994; Hansen and Martins, 1996). Although pure statistical stochastic processes such as Brownian motion and O-U process are not expected to model in detail all genetic factors responsible for phenotypic variation in a complex trait

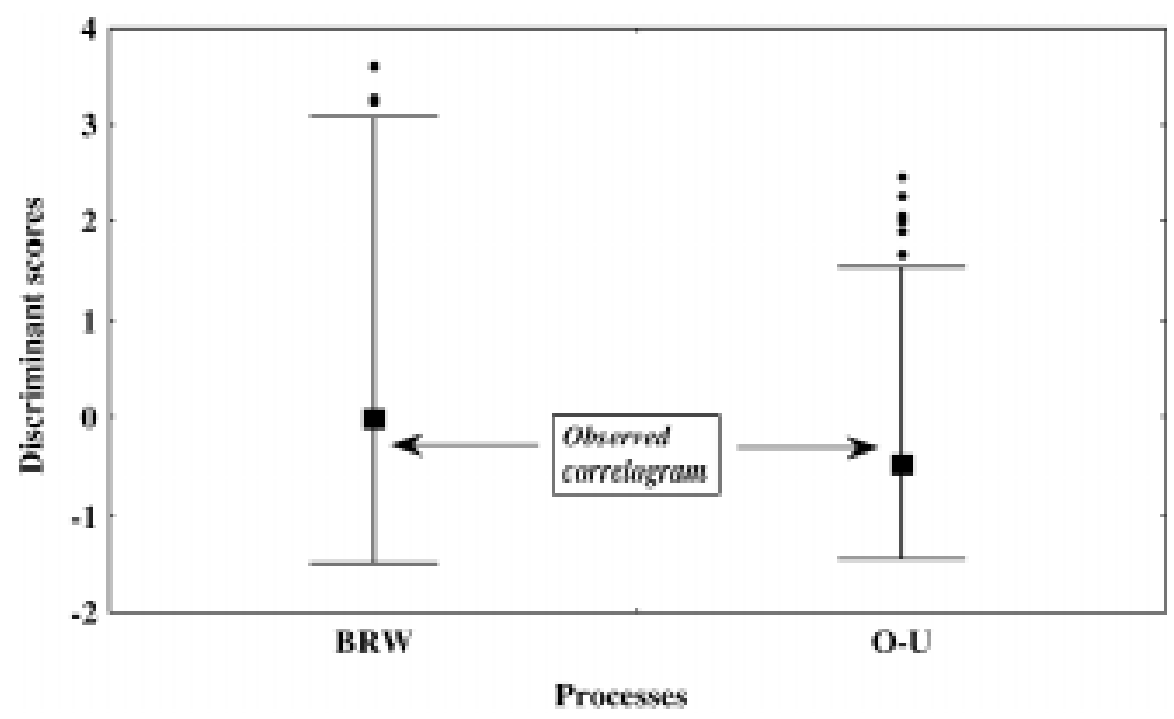

Figure 4 - Discriminant scores of the correlograms generated by simulations of Brownian motion (BRW) and O-U process of phenotypic evolution. The position of the score of the observed correlogram for the 19 species of South American owls is shown. 
such as body size (which explains the large residuals of discriminant analysis - Figure 4), they can give a first indication of the general evolutionary patterns and processes involved at very large time scales (Martins, 1994).

Brownian motion has usually been interpreted as an expression of genetic drift, although higher evolutionary rates than expected by pure neutral divergence can also indicate constant directional selection (Hansen and Martins, 1996). When considering the nature of the character analyzed and the large time scales in data, both processes are in fact unlikely to explain phenotypic variation. Body size is one of the most important characteristics of the organisms, being correlated with many other ecological, physiological and life-history traits, such as geographic range size, population density, home range, prey size, growth and metabolic rates, age at sexual maturity, number of offspring, among others (Peters, 1983; La Barbera, 1989; Brown, 1995). So, it would be improbable that, at these very large time scales, it evolves by simple genetic drift, or under unidirectional constant selective pressure. On the other hand, even at small time scales, stabilizing selection is usually involved in body size variation among species (Lynch, 1990; Spicer, 1993), which can be explained by the many structural, ontogenetic and physiological constraints involved in local adaptation after speciation events. These constraints imply that closely related species are similar (phylogenetic inertia), but adaptations to different environments tend to produce independent variation after those constraints have become inoperative (Cheverud et al., 1985; Schluter, 1996). So, long-term evolution under stabilizing selection is in fact a plausible explanation for the patterns observed in the correlograms of body size.
Phylogenetic correlograms have been used, since Gittleman and Kot's (1990) paper, as a method for detecting phylogenetic patterns in data (the diagnosis approach, in the sense of Gittleman and Luh, 1992). However, the theoretical paper of Hansen and Martins (1996) indicates that they can also be used as an inferential tool, at least for distinguishing simple processes, including the two discussed in this work (Brownian motion and $\mathrm{O}-\mathrm{U}$ process). The general idea (Figure 6) is that Brownian motion produces a monotonic decrease in Moran's I coefficients with increasing phylogenetic distance classes. When stabilizing selection, as modeled by the O-U process, is involved, it curves the correlogram, reducing the phylogenetic distance at which the line cuts the expected value of I under the null hypothesis (absence of autocorrelation). This effect may increase up to the level that history can be "forgotten" and no phylogenetic pattern can be detected in data, even among very closely related species. These curved profiles were in fact obtained in the simulations, reflecting in higher correlation (weaker gradients) between Moran's I and phylogenetic distance classes than observed for Brownian motion. The most difficult inferential aspect in the correlogram analysis should be to distinguish between evolutionary processes that can be modeled by Brownian motion (constant directional selection versus random drift) (Hansen and Martins, 1996). Further investigation of this topic is necessary, but there is a possibility that the increasing rate of evolution, associated with selection, may produce higher slopes in the correlogram. Another possibility, following the inferential procedures in spatial autocorrelation, is that multivariate (or multivariable) analysis can be useful to distinguish between different processes (Sokal and Jacquez, 1991).

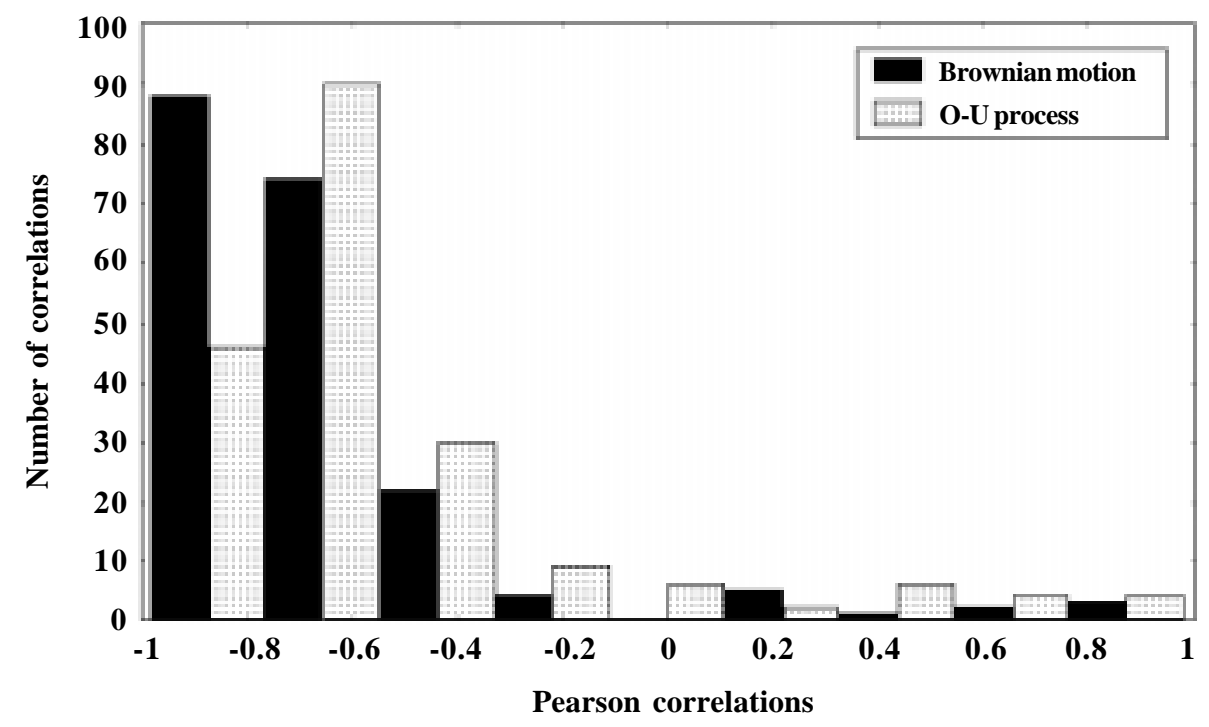

Figure 5 - Distribution of gradient correlations (Pearson correlations between Moran's I and phylogenetic distance) in the correlograms of simulated evolution generated by Brownian motion and $\mathrm{O}-\mathrm{U}$ process. 


\section{Theoretical correlogram}

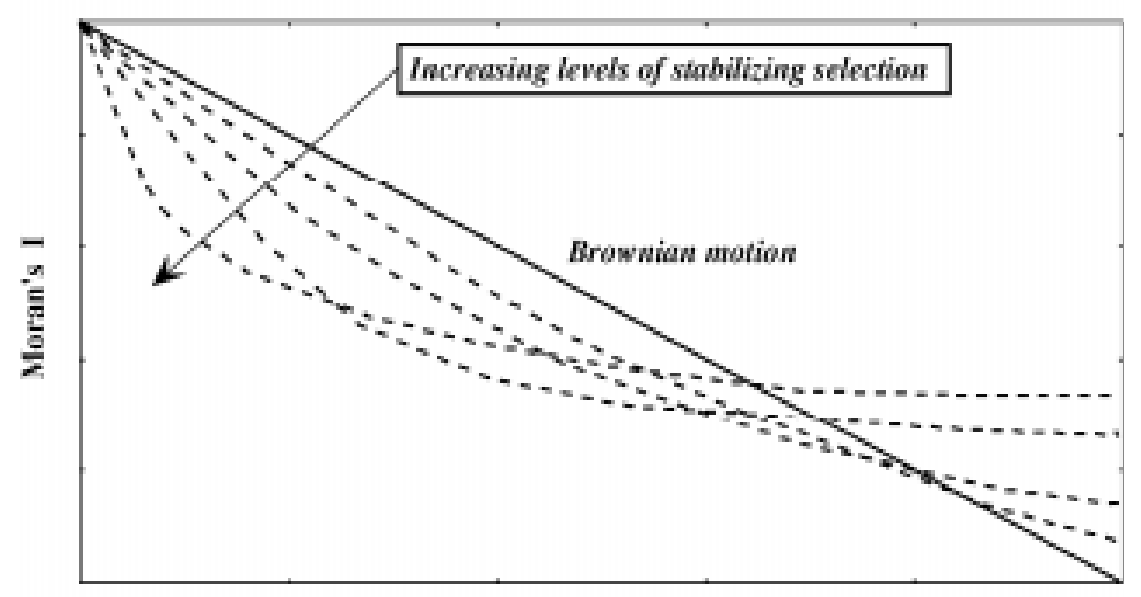

Phylogenetic distance

Figure 6 - Theoretical correlograms showing how increasing levels of stabilizing selection (in O-U process) distorts the monotonic correlogram that is expected under a Brownian motion. Curved dashed lines indicate different levels of stabilizing selection.

Other methods have been proposed to distinguish between Brownian motion and O-U processes, but their application in this study would be difficult, because of limitations in the data set. The approach by Martins (1994) fits the two models to phylogenetically independent contrasts between species against time, to avoid the problem of independence. However, the phylogeny used as a basis for this study possesses polytomies within genera, that could produce undesirable effects on model fitting procedures. On the other hand, methods based on testing evolutionary rates, assuming different genetic processes, such as proposed by Lynch (1990), Turelli et al. (1988) and Spicer (1993), need to compare within and among species variances. However, the within species variability is not available for the species analyzed here.

Although correlograms generated by the two processes are statistically different according to all analyses, their high overall similarity implies in a relatively low inferential power, in terms of predicting the process of origin for a given correlogram. A better classificatory ability than obtained in this paper would be achieved by increasing the number of distance classes, but this also needs a larger number of species and a fully resolved phylogeny among them. Nevertheless, comparison between observed and simulated correlograms can be an initial indicator of how complex data can be fitted to general statistical models and permit an initial understanding of the variability in a quantitative trait of a group of organisms, being useful even when fully resolved phylogenies and within species variability are not available.

\section{ACKNOWLEDGMENTS}

We thank E.P. Martins, L.M. Bini, C.M. Vieira and an anonymous reviewer for many valuable discussions on phyloge- netic comparative methods and critical suggestions to the original manuscript. Our research program in quantitative ecology and population biology has been continuously supported by the Conselho Nacional de Desenvolvimento Científico e Tecnológico $(\mathrm{CNPq})$ and Coordenação para Aperfeiçoamento do Ensino Superior (CAPES).

\section{RESUMO}

Nos últimos anos diversos modelos têm sido propostos a fim de realizar inferências sobre processos microevolutivos com base em padrões macroevolutivos obtidos a partir de dados comparativos. Dentre esses, o movimento Browniano e o processo Ornstein-Uhlenbeck (O-U) têm sido utilizados para modelar principalmente deriva genética e seleção estabilizadora, respectivamente. Esses modelos produzem curvas diferentes de relação entre variância interespecífica e distância no tempo, de modo que eles podem ser distingüidos com base em correlogramas filogenéticos. Neste trabalho, nós analisamos a variação interespecífica no tamanho do corpo de 19 espécies de corujas (Strigiformes) sul-americanas através de correlogramas filogenéticos, construídos utilizando índices I de Moran em quatro classes de distância. A filogenia entre as espécies foi definida com base em dados de hibridização de DNA. O correlograma observado foi então comparado a 500 correlogramas obtidos através de simulações de evolução por movimento Browniano e pelo processo $\mathrm{O}-\mathrm{U}$, sobre essa mesma filogenia. Esses correlogramas foram comparados entre si utilizando análises de variância (ANOVA e MANOVA) e através das correlações entre os índices I de Moran e as classes de distância filogenética. O correlograma observado indica a existência de um gradiente filogenético de variação até cerca de 45 milhões de anos, quando os índices se estabilizam, e é similar aos correlogramas obtidos através do processo O-U, considerando tanto a correlação do gradiente quanto a sua alocação aos dois grupos de processos através de análise discriminante. Esse padrão é esperado, considerando a importância do tamanho do corpo e sua correlação com diversos caracteres eco- 
lógicos e de história de vida, que produzem muitas restrições que podem de fato ser modeladas por um processo O-U expressando seleção estabilizadora.

\section{REFERENCES}

Brown, J.H. (1995). Macroecology. University of Chicago Press, Chicago. Cheverud, J.M., Dow, M.M. and Leutenegger, W. (1985). The quantitative assessment of phylogenetic constraints in comparative analyses: sexual dimorphism in body weight among primates. Evolution 39: 1335-1351.

Diniz-Filho, J.A.F. (1998). Análise de Autocorrelação Espacial: Inferências Microevolutivas e Aplicações em Genética de Populações. Série Monografias No. 6. Sociedade Brasileira de Genética, Ribeirão Preto, pp. 83-145.

Diniz-Filho, J.A.F. and Sant'Ana, C.E.R. (1998). Macroecological analysis of South American owls (Strigiformes) using phylogenetic independent contrasts. J. Comp. Biol. 3: 27-32.

Dunning, J.S. (1989). South American Birds. Harrowood Books, London.

Felsenstein, J. (1985). Phylogenies and the comparative method. Am. Nat. 125: $1-15$

Felsenstein, J. (1988). Phylogenies and quantitative characters. Ann. Rev. Ecol. Syst. 19: 445-471.

Gittleman, J.L. and Kot, M. (1990). Adaptation: statistics and a null model for estimating phylogenetic effects. Syst. Zool. 39: 227-241.

Gittleman, J.L. and Luh, H.-K. (1992). On comparing comparative methods. Ann. Rev. Ecol. Syst. 23: 383-404.

Gittleman, J.L., Anderson, C.G., Kot, M. and Luh, H.-K. (1996). Phylogenetic lability and rates of evolution: a comparison of behavioral, morphological and life-history traits. In: Phylogenies and the Comparative Method in Animal Behavior (Martins, E.P., ed). Oxford University Press, Oxford,pp. 166-205.

Hansen, T.F. and Martins, E.P. (1996). Translating between microevolutionary process and macroevolutionary patterns: the correlation structure of interspecific data. Evolution 50: 1404-1417.

Johnson, R.A. and Wichern, D.W. (1992). Applied Multivariate Statistical Analysis. Prentice-Hall, New Jersey.
Jones, J.A., Dickerman, A.W. and Garland, T. (1993). PDAP: Phenotypic Diversity Analysis Program. University of Wisconsin, Madison (Distributed by the authors).

La Barbera, M. (1989). Analyzing body size as a factor in ecology and evolution. Ann. Rev. Ecol. Syst. 20: 97-117.

Lynch, M. (1990). The rate of morphological evolution in mammals from the standpoint of neutral expectation. Am. Nat. 136: 727-741.

Martins, E.P. (1994). Estimating the rate of phenotypic evolution from comparative data. Am. Nat. 144: 193-209.

Peters, R.H. (1983). The Ecological Implications of Body Size. Cambridge University Press, Cambridge.

Sant'Ana, C.E.R. and Diniz-Filho, J.A.F. (1997). Autocorrelação filogenética para o tamanho do corpo em corujas (Strigiformes) da América do Sul. Ararajuba (Rev. Bras. Ornitol.) 5: 39-43.

Schluter, D. (1996). Adaptive radiation along genetic lines of least resistance. Evolution 50: 1766-1774.

Sibley, C.G. and Ahlquist, J.E. (1990). Phylogeny and Classification of Birds. Yale University Press, New Haven.

Sibley, C.G. and Monroe, B.L. (1990). Distribution and Taxonomy of Birds of the World. Yale University Press, New Haven.

Sick, H. (1997). Ornitologia Brasileira. Nova Fronteira, Rio de Janeiro.

Sokal, R.R. and Jacquez, G.M. (1991). Testing inferences about microevolutionary processes by means of spatial autocorrelation analysis. Evolution 45: 152-168

Sokal, R.R. and Oden, N.L. (1978a). Spatial autocorrelation in biology. I. methodology. Biol. J. Linn. Soc. 10: 199-228.

Sokal, R.R. and Oden, N.L. (1978b). Spatial autocorrelation in biology. II. Some biological implications and four applications of ecological and evolutionary interest. Biol. J. Linn. Soc. 10: 229-249.

Sokal, R.R. and Rohlf, F.J. (1995). Biometry. 3rd edn. W.H. Freeman, New York.

Spicer, G.S. (1993). Morphological evolution of the Drosophila virilis species group as assessed by rate tests for natural selection on quantitative characters. Evolution 47: 1240-1254.

Turelli, M., Gillespie, J.H. and Lande, R. (1988). Rate tests for selection on quantitative characters during macroevolution and microevolution. Evolution 42: 1085-1089.

(Received April 29, 1999) 